\title{
Skull Base Langerhans Histiocytosis with Diabetes Insipidus and Panhypopituitarism - A Rare Clinical Entity
}

Anirban Ghosh, ${ }^{1}$ Mithun Chaudhury, ${ }^{2}$ Abhishek Mukherjee ${ }^{3}$

\begin{abstract}
$\underline{\text { Introduction }}$
A case of Langerhans cell histiocytosis (LGH) involving extensive area of base of skull resulting in panhypopituitarism and diabetes insipidus (DI) is reported.

\section{Case Report}

A 16 year old male presented with diminished vision, bilateral ptosis, left sided lateral rectus palsy, hypoesthesia of trigeminal nerve with nasal obstruction for last 5 months. There was polypoidal, bleeding mass in both nasal cavities. Contrast enhanced CT Scan showed a large homogenous mass arising from sphenoid extending into cavernous sinus and the suprasellar region. Endoscopic nasal biopsy revealed abundant Langerhans cell histiocytes, macrophages, neutrophils. Chemotherapy and radiotherapy were administered. But within 2 months the patient presented with Cushingoid features and further diminution of vision. Detailed work-up revealed Hypogonadotrophic hypogonadism and diabetes insipidus. Debulking of the tumour was done and left optic nerve decompression was done. PET scan was performed and showed large, well defined mass with increased FDG uptake in the skull base with suprasellar extension, reaching upto petrous temporal bone and causing bony erosion of ethmoid and sphenoid sinuses. Patient was then advised adjuvant chemotherapy.

$\underline{\text { Discussion }}$

Langerhans cell histiocytosis is a rare group of disorders characterised by abnormal clonal proliferation and accumulation of abnormal dendritic cells. Involvement of base of skull is even rarer. Though diabetes insipidus has been reported in Langerhans cell histiocytosis involving pituitary, panhypopituitarism is rare. These combinations of extensive Langerhans cell histiocytosis of base skull with clinical features of Diabetes insipidus and panhypopituitarism makes this case a rare clinical entity.

$\underline{\text { Keywords }}$

Myeloproliferative Disorders; Langerhans Cell Histiocytosis; Hypogonadism; Diabetes Insipidus; Skull Base.
\end{abstract}

\section{$\underline{\text { ABSTRACT }}$}

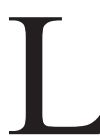
angerhans cell histiocytosis (LCH) is a part of a group of disorders called Histiocytosis characterised by abnormal proliferation of histiocytes. These cells are epidermal dendritic cells derived from bone marrow. LCH is manifested either as single bone disease or as multisystem multi organ disorder with clinical features of fever, lethargy, lytic

1 - Hope nursing home, Raniganj

2 - Medica Superspeciality Hospital, Kolkata

3 - Suraksha Diagnostics, Kolkata

\section{Corresponding author:}

Dr Anirban Ghosh

email: way2anirban@gmail.com bone lesions. It is also known as Eosinophilic granuloma, Hand-Schuller Christian disease, Letterer- Siwe disease.

\section{Case Report}

A 16 year old male presented with diminished vision, bilateral ptosis, left sided lateral rectus palsy (Fig. 1), hypoesthesia of trigeminal nerve with nasal obstruction for last 5 months. On examination, the patient showed normal strength of upper and lower limbs, hypotonia, hyperreflexia and dorsiflexion in plantar reflex. There was polypoidal, bleeding mass in bothnasal cavities. Contrast enhanced CT Scan showed a large homogenous mass arising from sphenoid extending into cavernous 


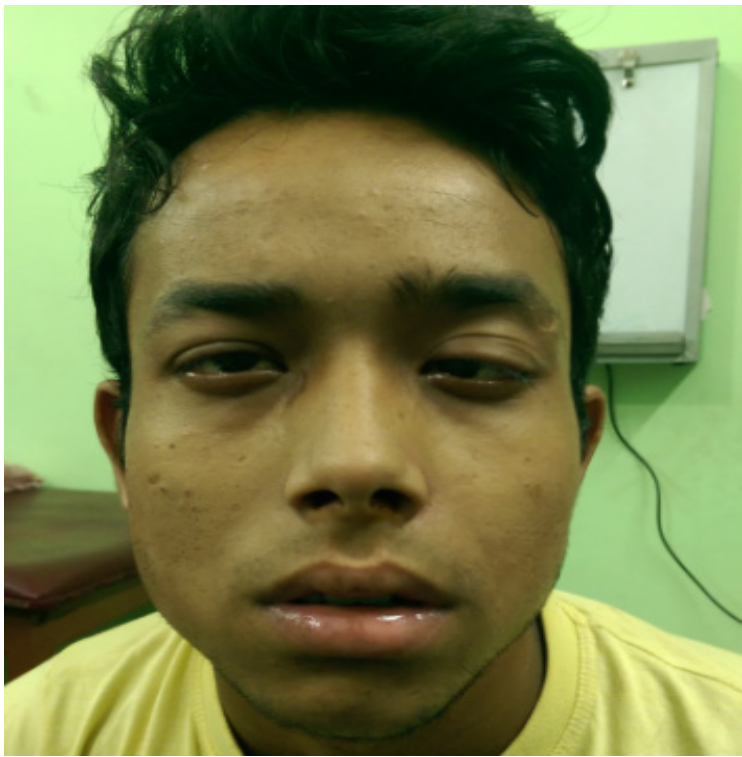

Fig. 1. Clinical photograph showing bilateral ptosis and left lateral rectus palsy

sinus and the suprasellar region, superiorly reaching upto optic chaisma, inferiorly extending upto hard palate, anteriorly occupying posterior nasal cavity (Fig. 2). Endoscopic nasal biopsy revealed abundant Langerhans cell histiocytes, macrophages, neutrophils (Fig. 3). Chest X-ray, skeletal survey, abdominal scans were normal.

Chemotherapy and radiotherapy were administered. But within 2 months the patient presented with

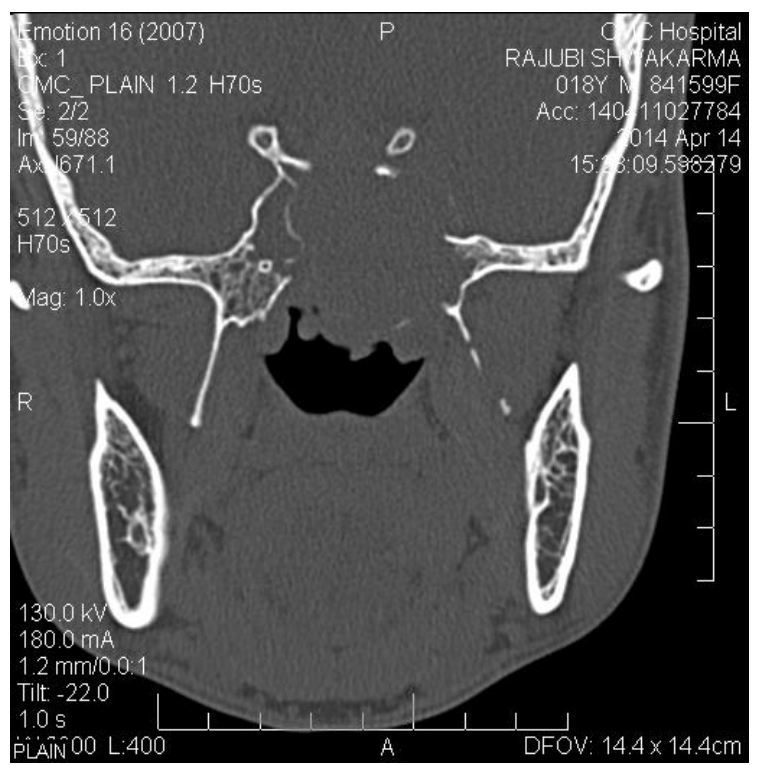

Fig.2. Coronal CT Scan showing isodense lesion in sphenoid (left>right) with extension into lateral recess, choana, destruction of lateral wall and involvement of left orbital apex

Cushingoid features and further diminution of vision. Detailed work-up revealed hypogonadotrophic hypogonadism and diabetes insipidus. CECT revealedthat the mass extended into suprasellar region, posteriorly upto clivus, involvement of both optic nerves and erosion of both ethmoids and sphenoids. MRI showed a predominantly T2 hypointense mass in the sphenoid sinus extending to the left orbital apex and compression of the left temporal lobe (Fig. 4) and

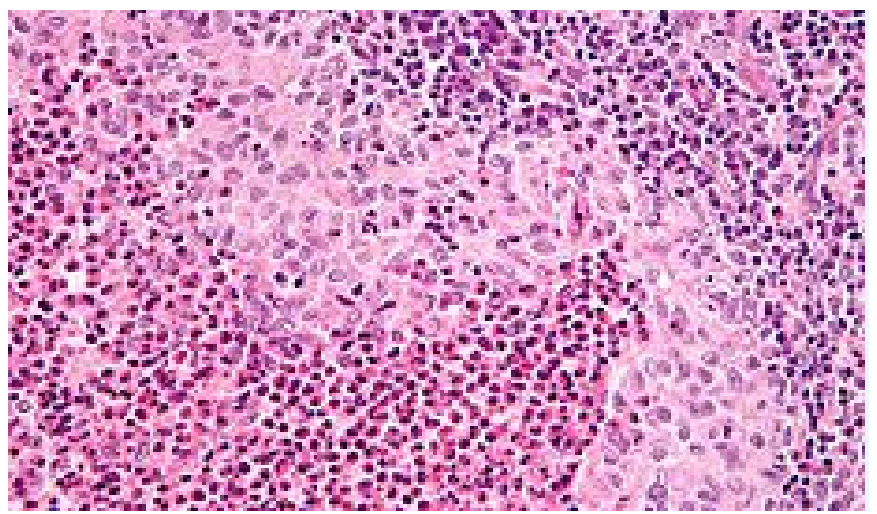

Fig.3. Photomicrograph of nasal tissue biopsy showing distension of nodal sinuses by reniform Langerhans cell surrounded by rims of abundant eosinophils (H\&E, 40X) 


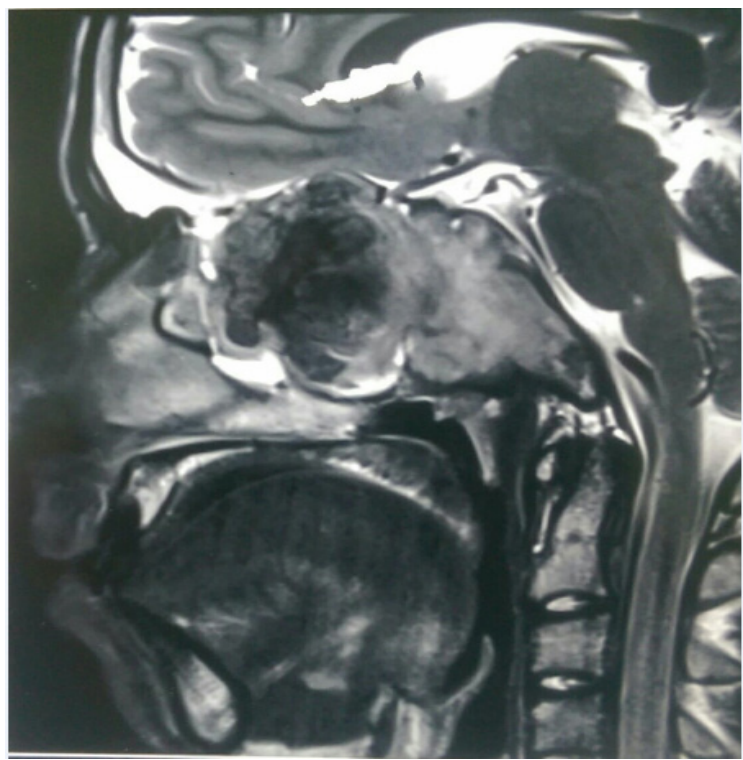

Fig.4. Axial cut MRI showing predominantly T2 hypointense left sided sphenoid mass extending into left orbital apex and causing compression of left temporal lobe

extension into the clivus (Fig. 5).

Visual acuity in the right eye was diminished to finger counting close to the face and on the left side, it was $6 / 18$. Debulking of the tumour was done and left optic nerve decompression was done. There was erosion of cribriform plate and lateral wall of sphenoid; no bone was found between dura and the mass. Patient developed exacerbation of diabetes insipidus that was managed with hydrocortisone and desmopressin.

PET scan was performed and showed large, well defined mass with increased FDG uptake in the skull base with suprasellar extension, reaching upto petrous temporal bone and causing bony erosion of ethmoid and sphenoid sinuses. Patient was then advised adjuvant chemotherapy.

\section{Discussion}

LCH may be unisystem (monoostotic or polyostotic) or multisystem multifocal. Unisystem LCH or Eosinophilic granuloma typically presents as slowly progressive lytic lesion of bones, generally involving skull bones, upper extremity long bones, ribs, pelvis, vertebrae. ${ }^{1}$ Sphenoid

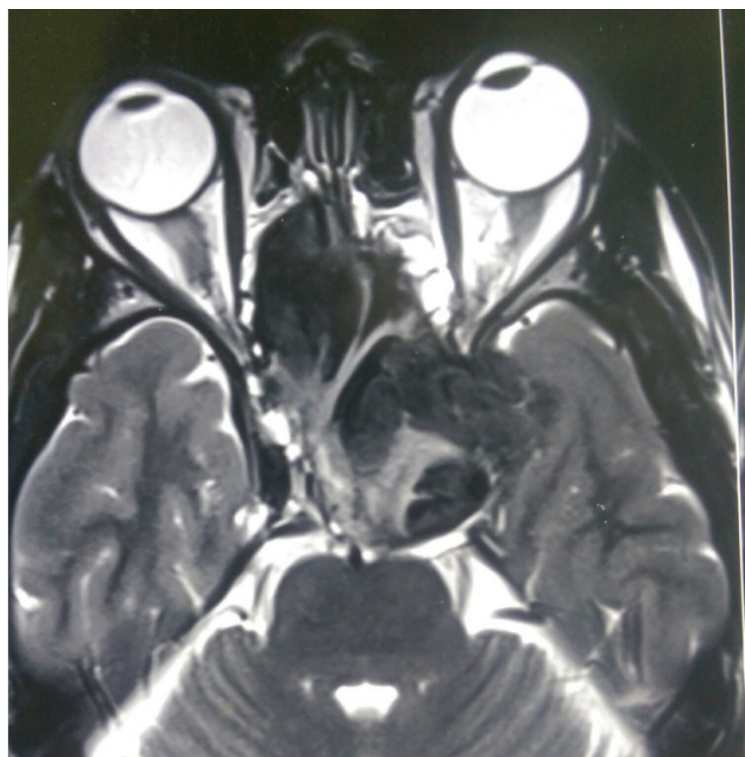

Fig.5. Sagittal section MRI showing heterogenous mass on $\mathrm{T} 2$ involving the sphenoid sinus and clivus

sinus involvement is extremely rare; ${ }^{2}$ involvement of clivus, petrous apex have also been reported. ${ }^{3}$ Orbit involvement is also reported. ${ }^{4}$ In the present case involvement of sphenoid sinus, extension into cavernous sinus, parasellar, suprasellar region, orbit, petrous apex have been noted.

LCH usually affects patients of 1-10 years of age with peak incidence between 5-10 years and incidence of 1 in 2,00,000,; even rarer in adults with incidence of $1: 5,60,00$. It is sporadic and non- hereditary. Multisystem disease usually affects patients aged less than 2 years and bears poorer prognosis.

Debate continues regarding the pathogenesis of $\mathrm{LCH}$, whether reactive or neoplastic process. Comparative favourable prognosis, release of cytokines point towards reactive aetiopathology; ${ }^{5}$ whereas clonal proliferation of BRAF proto-oncogene in $57 \%$ of $\mathrm{LCH}$ biopsies ${ }^{6}$ classifies LCH as "Myeloproliferative disorder".

Clinically it produces non-specific inflammatory response resulting in fever, lethargy, weight loss. Bone involvement causes painful bone swelling, pathologic fractures due to osteolytic lesion. Skin rash in intertriginous region as scaly erythematous lesion to 
red papules is seen in $80 \%$ patients of LCH. $50 \% \mathrm{LCH}$ patients present with lymphnode enlargement and 20\% to $30 \%$ present with hepatosplenomegaly. Most common CNS affection in LCH is hypothalamic- pituitary axis and cerebellum. ${ }^{7}$ Less commonly meninges and brain parenchyma of temporal and occipital lobes are involved either by direct extension or by spread through epidural space. ${ }^{8}$ Diabetes insipidus is the most common endocrine manifestation of LCH. About $23 \%$ of LCH patients will have diabetes insipidus due to lack of AntiDiuretic Hormone (ADH); more commonly seen in multisystem disorder and especially with skull and orbit involvement. ${ }^{9}$ Diabetes insipidus is caused by posterior pituitary infiltration by Langerhans cells causing local tissue damage by increased amount of Interleukin-2 (IL2), Prostaglandin E2 (PGE-2).

Radiologically, both CT Scan and MRI are important tools for identifying and delineating boundaries of the disease process. At an early stage, the lesion and the brain parenchyma remain isodense in appearance on CT Scan, making it difficult to identify the lesion and its extent. MRI shows the mass isointense or hypointense to normal brain tissue with brilliant enhancement with Gadolinium contrast, thus making it investigation of choice. ${ }^{8}$ It also shows thickening of pituitary stalk with granulomatous mass lesion in the region of hypothalamus with absence of posterior pituitary bright spot.

Diagnosis is definitely histological. Presence of Langerhans cells with distinctive margin, pink granular cytoplasm accompanied by varying number of neutrophils, macrophages and multinucleated giant cells best visualised in Papanicolaou stain is the hallmark of diagnosis. A definitive diagnosis can be made by demonstrating Birbeck's granules in electron microscopy and positivity for Cluster Differentiation (CDI) antigen. ${ }^{10} \mathrm{~S}-100$ protein and MHC-II expression are also noticed in $\mathrm{LCH}^{11}$
Treatment in solitary lesion is essentially excision and low dose radiotherapy. Mutifocal multisystem $\mathrm{LCH}$ requires chemotherapy. Prognosis of LCH is usually favourable, however young age at diagnosis, hepatosplenomegaly, thrombocytopenia, polyosteotic disease have poor prognosis.

\section{References}

1. Stull MA, Kransdrorf MJ, Devaney KO. Langerhans cell histiocytosis of bone. Radiographics: a review publication of the Radiological Society of North America, Inc 1992 July 12(4):801-23

2. Yu G, Huang F, Kong L, Kong X, Zhang L, Xu Q. Langerhans cell histiocytosis of the sphenoid sinus: a case report. Turk J Pediatr. 2010 Sep-Oct; 52(5):548-51

3. 3, Krishna H, Behari S, Pal L, Chhabra AK, Banerji D, Chhabra DK, Jain VK. Solitary Langerhans-cell histiocytosis of the clivus and sphenoid sinus with parasellar and petrous extensions: case report and a review of literature. Surg Neurol. 2004 Nov; 62(5):447-54

4. Shetty SB, Mehta C. Langerhans cell histiocytosis of the orbit. Ind J Ophthalmology 2001; 49(4):267-8

5. Broadbent V, Davies EG, Heaf D, et al. Spontaneous remission of multisystem histiocytosis-X. Lancet 1984; 8371:253-4

6. Badalian-Very G, Vergilio JA, Degar BA et al. Recruitment of BRAF mutations in Langerhans cell histiocytosis. Blood 2010; 116(11):1919-23

7. Favara BE, Jaffe R. Pathology of Langerhans cell histiocytosis Hematol Oncol Clin North Am. 1987; 1:75-97

8. Graif M, Pennock JM. MR imaging of histiocytosis $\mathrm{X}$ in the central nervous system. AJNR Am J Neuroradiol. 1986; 7:21-3

9. Dunger DB, Broadbent V, Yeoman E, et al. The frequency and natural history of diabetes insipidus in children with Langerhans cell histiocytosis. N Engl J Med. 1989; 321: 1157-62

10. Kramer TR, Noecker RJ, Miller JM, Clark LC. Langerhans cell histiocytosis with orbital involvement. Am J Ophthalmol. 1997; 124:814-24

11. Pohar-Marinsek Z, Us-Krasovec M. Cytology of Langrehans cell histiocytosis. Acta Cytol. 1996; 40:1257-64. 